\title{
Influence of Internet-Based Tools on Students' Performance in Biology in Public Secondary Schools in Likuyani, Kakamega County Kenya
}

\author{
Kiyeng Edwin ${ }^{1}$, Dr. Kimamo Githui ${ }^{2}$, Dr. Benson Njoroge ${ }^{3}$ \\ ${ }^{1}$ Master of Education Degree in Instructional Technology \\ ${ }^{2}$ Lecturer Mount Kenya University \\ ${ }^{3}$ Lecturer Mount Kenya University
}

\begin{abstract}
Candidates have been scoring low grades in Biology Likuyani sub-county. Therefore, the research sought to assess the influence of internet-based tools on students' performance in Biology in public secondary schools in Likuyani, Kakamega County. The objective of the study was; to find out the Influence of Internet-based tools. The study assumed that the target groups are readily available within the study area. This study employed mixed methodology and descriptive survey were used to generate both qualitative and quantitative data from public secondary schools in Likuyani Sub-County based on study objectives. The sample size for this study was 321 respondents. The instruments which were used include; questionnaires, interview schedule, observation check list and document analysis. Content validity was determined using constructive criticism by professionals from department of Educational Psychology and Technology of Mount Kenya University. Piloted data were used to test for reliability using Split half type of reliability test. The test questions were divided into two parts using odd numbers and even numbers. The divided questions were administered to respondents and score of each half were correlated using Cronbarch Alpha. Collected data were coded into SPSS software version 24 and cleaned and data were analyzed using descriptive statistics.The study findings showed that internet-based tools were statistically significant with a positive influence on students' performance in Biology. The study findings concluded that that Internet problem solving in ICT, Internet search and Teaching machines integration in ICT enhances student's performance. From the findings of the study, it was recommended that; teachers to be given sufficient training on how to use ICT in teaching and learning processes to acquire the requisite knowledge and skills in integrating the technology in classrooms.
\end{abstract}

Key words: performance, internet-based, tools, public secondary schools, students, biology

\section{BACKGROUND TO THE STUDY}

$\mathrm{S}$ tudent performance remained the outcome for learning a learner, instructor or institute accomplishes its Instructive objectives. Teaching accomplishment normally estimated by examinations or constant evaluations however; there is no expansive admission to how it is best attempted or which point of view is most imperative procedural learning, for instance, aptitudes or decisive information, for instance, realities (Ward, Stoker \& Ward, 2014). Academic performance was the outcome that demonstrated how much an individual had achieved explicit objectives that were the purpose of combination of exercises in instructional conditions, particularly in school, college and university (Schneider \& Preckel, 2017).

To achieve this academic performance schools should put in place strategies which will lead to best performance according to the current situation of the world. For now, the world is heading towards modern technology where there is need for implementation of technology in all schools in the country as Jubilee Government promised laptop distribution to all schools in their 2013 manifesto.

In Kenya ICT foundation for the most part alludes to systems, links, remote connections or satellite dishes, just as other critical components, for example, ideal utilization of these physical resources (interconnection of various systems or the administration of the recurrence range) and their support. Social, financial, and innovative changes of the previous decades are making instruction and preparing for all more essential than any time in recent memory. However educational frameworks to various degrees in Kenya, are attempting to bear the cost of instructive open doors for all, to give their alumni the important information and aptitudes for advancing commercial centers and complex living conditions, and to get ready subjects for deep rooted learning. To address these difficulties, the nation needs to concentrate simultaneously on growing access, enhancing interior productivity, advancing the nature of educating and learning, and enhancing framework the executives such as laptop projects which were implemented in Kenya in 2013 for primary schools. In secondary school computer studies has been examinable in national examination council, Kundhlande (2015). This is on the grounds that educational frameworks around the globe are on expanding strain to utilize the new information and communication technologies (ICTs) and therefore tasked for the outcome. Learners need to master Biology in order to fully comprehend the current change in technology in the world and make informed decisions. Biology offers students an opportunity to build up their basic reasoning and analytical skills to achieve their full potentials, (Republic of Kenya 1999) recommended that education should prepare learners for industrialization by 2030. 
However, performance in Biology has continuously been declining especially in Likuyani, Kakamega County for the last few years Biology compared Likuyani Sub County. This raised the question on what type of instructional media the sub-county employed during teaching and learning process? Current teaching TM embraced cramming of content theoretically. This constant decline in performance created a gap in teaching and learning process of the subject. Teachers and learners may have had varied views on the results in totality of Biology based on availability and utilization of the ICT materials and its implications on students' performance in the entire sub-county. This called for an attention to ascertain the cause of the worrying decline in Biology at Kenya national examination council (KNEC) level in Likuyani. Therefore, this current study sought to assess the influence of internet-based tools on students' performance in Biology in public secondary schools in Likuyani, Kakamega County.

\section{Statement of the Problem}

Students have been attaining low grades in Biology for the last few years consecutively throughout country and more so in Kakamega County particularly Likuyani sub county. Much mitigation had been conducted to address this low performance to Biology. The point of the SMASSE program was to integrate computer technology in teaching and learning sciences for better student accomplishment in Likuyani SubCounty, notwithstanding the SMASSE preparing, MOE chose and furnished five optional schools with assets through Economic Stimulus Package to manufacture ICT framework and to enhance limit working of educators in the chosen schools on combination of personal computers innovation in educating and learning. Different schools had likewise obtained PCs through the focal point of greatness finances given to the schools by the MOE, Constituency Development Fund grants (C. D. F) or gifts. Lesson study was conducted by Biology teachers to address weakness and strengths of teachers and learners in enhancing performance. The county government of Kakamega in liaison with TSC conducted workshops of all Biology teachers to improve the execution of Biology. Despite all these, the performance of Biology was still low. However, if this crisis was not addressed many students in Likuyani sub-county were left out from studying competitive careers like medicine. Therefore, the study sought to assess the influence of internet-based tools on students' performance in Biology in public secondary schools in Likuyani, Kakamega County.

\section{Research Objective}

To examine the influence of internet-based tools on students' performance in Biology in public secondary schools in Likuyani, Kakamega County.

\section{Research question}

i. What is the influence of Internet search online on students' performance in Biology in public secondary schools in Likuyani, Kakamega County?

\section{LITERATURE REVIEW}

This section looks at the theoretical framework, the conceptual framework and empirical review

\section{Empirical Review}

\section{Influence of Internet - Based Tools on Students' Performance in Biology}

Learning device is characterized as any product or online instrument or administration that is utilized either for your very own or proficient learning, for educating or training (Witten, Frank, Hall \& Pal, 2016). Delaney, O'Keeffe and Fragou (2017), indicates that, the innovative organizations are molding the worldwide engineering education trends and practices, they support the up-and-coming age of designing experts through creative innovative engineering educational products and services aimed at teachers and students globally.

Rajaonah (2017) noted that there are so many internet-based information and communication platforms providing access to search engines for example Google scholar, database and other learning applications. These instruments utilize the intensity of web-based life to enable students to learn and educator's interface. Examples of companies which provide WBLE platforms also suitable for Biology teaching and learning include: Autodesk, Agilent Technologies, Dassault systems, National Instruments, Sun-micro systems, Learning, Infosys, and Bosch. Other Biology platforms include BlogSpot .com, WebCrawler search engine for Biology, ERASYSAPP, Web quest provide information on cell division, model-Apps for phones collaborative learning tools concept maps and community initiative, a web quest epidemic provide students with information on disease conditions.

The Web Quest is an Engine for Biology education. Concept mapping is a recommended teaching strategy for Biology education. Because of the wideness of Biology topics, most of these search engines limit themselves to a particular topic example cellular Biology (study of the cells), Botany (study of plants), zoology (study of animals), Anatomy and Physiology (study of the body organs and their functions) etc. The Biology teachers can choose from any of tools to suit their lesson, such Web site should be checked by the Biology teacher prior to the lesson to ensure that the tool is capable for producing whatever information the teacher wants her students to know (Sumich \& Pinkard-Meier, 2016). The Biology teacher can also download the information using a $\mathrm{CD}$ - ROM and projector after editing to transfer the information needed. Finding materials and assets is routinely referred to by instructors as a critical action in the main phases of arranging and has been appraised as a key part of their arranging procedure (Mandinach \& Gummer, 2016). In describing the attributes of successful teachers, Mandinach and Gummer (2016) indicated that the abilities of these teachers to accumulate content for their courses from various sources can prompt better execution. Nonetheless, educators have reliably communicated a requirement for help with 
finding materials and view their absence of capability around there as a factor that constrains their classroom teaching adequacy (Mandinach\& Gummer, 2016).

\section{Conceptual Framework}

According to Ravitch (2012), a conceptual framework is an analytical instrument with a few varieties and settings. It is utilized to make conceptual distinctions and compose thoughts. This examination will adopt a conceptual framework where independent variables are itemized as internet-based tools whereas the dependent variables were indicated as students' performance in Biology. On the other hand, the intervening variable were indicated as the government policies, school management, attitude and motivation as illustrated in Figure 1

\section{Independent variable}

\section{Dependent variable}

\section{Internet-based tools \\ $\checkmark$ Internet search online \\ $\checkmark$ YouTube \\ $\checkmark \quad$ Teaching machines}

\section{RESEARCH METHODOLOGY}

This study employed mixed methodology. This enabled the study to generate both qualitative and quantitative data from public secondary schools in Likuyani, Kakamega County based on study objectives.

\section{Research Design}

The investigation embraced a descriptive survey research design. The design was used to collect information by administering questionnaires to a sample of individuals. The design was chosen for the research study as it gives the study a possibility to observe the ICT integration in a completely natural and unchanged natural environment.

\section{Target Population}

The study was conducted in government secondary schools because public secondary schools have the highest number of students. The accessible population of this study comprise of the 29 public secondary schools' principals, 4523 students, and 72 Biology teachers.

\section{Sampling Procedures and Sample Size}

\section{Sample Size}

The study sampled 1523 form three students as a sample since form one and two have not done much in Biology syllabus and the form four are preparing for their KCSE,

This study obtains sample size using Yamane formulae (1967).

$$
n=\frac{N}{1+N(e)^{2}}
$$

Where $\mathrm{n}$ is the sample size required

\section{Students' Academic performance in Biology \\ - Mean grades}

Figure 1 Conceptual Framework

$$
\begin{aligned}
& \mathrm{N} \text { is the population size }=1624 \\
& \mathrm{e} \text { is the level of precision }=0.05 \\
& \mathrm{n}=1624 /\left(1+1624 * 0.05^{2}\right) \\
& \mathrm{n}=321
\end{aligned}
$$

Therefore, the sample size for this study was 321 respondents.

\section{Research Instruments}

The research instruments that were used in this study were questionnaires, interview schedule, and observation guide and document analysis.

\section{Pilot Testing}

Piloting of research instruments were carried out in one of the public secondary schools in Kakamega County that was not be involved in the main study, in order to ascertain validity and reliability of the research instruments. The researcher administered questionnaires to $10 \%$ of form three students. The researcher further interviewed the of Biology teachers.

\section{Validity of the Research Instruments}

Content validity were determined using constructive criticism from a team of three experts from department of Educational Psychology and Technology of Mount Kenya University

\section{Reliability of Research Instruments}

Reliability was ensured through piloting of research instruments in one of the government secondary schools in Kakamega County. Piloted data were used to test for reliability using Split half type of reliability test. Randomly, the test questions were divided into two parts using odd numbers and even numbers. The divided questions were administered to respondents and score of each half were correlated using Cronbarch Alpha the results of the piloted research instruments empowered the investigation to decide 
the consistency of reactions to be made by respondents and alter the things in like manner by updating the document. Research instruments were created cautiously to fit the examination structure and the arrangement of data analysis with the goal that the data collected to encourage the replying of research questions.

\section{Data Analysis Procedures}

Collected data were coded into SPSS software version 24, cleaned and managed before data analysis. Data were analyzed using descriptive statistics. Descriptive statistics included frequency, percentages, mean, median and standard deviation. Qualitative data were analyzed thematic method. The responses from interview schedule and observation schedule were grouped into themes and discussion done basing on the study objectives to draw conclusions.

\section{FINDINGS AND DISCUSSIONS}

Influence of Internet-based tools on students' performance in Biology

The study sought the student's perception in regard to the influence of Internet-based tools on students' performance in Biology. This was on a 5-point Likert scale, where: $5=$ strongly agree; 4 Agree; $3=$ Neutral; 2= Disagree and 1= strongly Disagree. The means and standard deviations values were established to enable the researcher make inferences concerning the study variable. The finding from the analysis was as presented in Table 1.

Table1: Students Response on the Influence of Internet-Based Tools on Students' Performance in Biology

\begin{tabular}{|c|c|c|c|c|c|c|c|c|}
\hline Statements & & SA & $\mathbf{A}$ & UD & D & SD & Mean & SD \\
\hline \multirow{2}{*}{$\begin{array}{l}\text { 1. Internet Endnote in ICT can enhance students' performance } \\
\text { in Biology }\end{array}$} & $\mathrm{F}$ & 123 & 105 & 9 & 4 & 5 & 4.37 & 0.806 \\
\hline & $\%$ & 50 & 42.7 & 3.7 & 1.6 & 2.0 & & \\
\hline \multirow{2}{*}{$\begin{array}{l}\text { 2. Internet Endnote in has negative impact on students' } \\
\text { performance }\end{array}$} & $\mathrm{F}$ & 83 & 46 & 24 & 50 & 43 & 2.30 & 1.534 \\
\hline & $\%$ & 33.7 & 18.7 & 9.8 & 20.3 & 17.5 & & \\
\hline \multirow{2}{*}{$\begin{array}{l}\text { 3. Internet search online take a lot of time which would affect } \\
\text { students' performance in Biology }\end{array}$} & $\mathrm{F}$ & 80 & 69 & 21 & 52 & 24 & 2.52 & 1.384 \\
\hline & $\%$ & 32.5 & 28.0 & 8.5 & 21.1 & 9.8 & & \\
\hline \multirow{2}{*}{$\begin{array}{l}\text { 4. Internet search can enhance students' performance in } \\
\text { Biology }\end{array}$} & $\mathrm{F}$ & 119 & 95 & 17 & 10 & 5 & 4.27 & 0.909 \\
\hline & $\%$ & 48.4 & 38.6 & 6.9 & 4.1 & 2.0 & & \\
\hline \multirow{2}{*}{$\begin{array}{l}\text { 5. YOU-TUBE is good ICT practice that can enhance students' } \\
\text { performance in Biology }\end{array}$} & $\mathrm{F}$ & 91 & 87 & 32 & 28 & 8 & 3.91 & 1.116 \\
\hline & $\%$ & 36.9 & 35.4 & 13 & 11.4 & 3.3 & & \\
\hline \multirow{2}{*}{$\begin{array}{l}\text { 6. YOU-TUBE can be a waste of time and may not enhance } \\
\text { students' performance in } \\
\text { 7. Biology }\end{array}$} & $\mathrm{F}$ & 85 & 65 & 26 & 47 & 23 & 3.58 & 1.373 \\
\hline & $\%$ & 34.6 & 26.4 & 10.6 & 19.1 & 9.3 & & \\
\hline \multirow{2}{*}{$\begin{array}{l}\text { 7. Teaching machines integration in ICT can improve students' } \\
\text { performance in Biology }\end{array}$} & $\mathrm{F}$ & 111 & 112 & 13 & 8 & 2 & 2.300 & 0.784 \\
\hline & $\%$ & 45.1 & 45.5 & 5.3 & 3.3 & 0.8 & & \\
\hline \multirow{2}{*}{$\begin{array}{l}\text { 8. Teaching machines in ICT may not improve students' } \\
\text { performance in Biology }\end{array}$} & $\mathrm{F}$ & 72 & 87 & 21 & 51 & 15 & 3.600 & 1.269 \\
\hline & $\%$ & 29.3 & 35.4 & 8.5 & 20.7 & 6.1 & & \\
\hline
\end{tabular}

Table 2 shows student's perception in regard to the influence of Internet endnote in ICT can enhance students' performance in Biology shows that $123(50 \%)$ strongly agree of the respondents, $105(42.7 \%)$ agree, $9(3.7 \%)$ undecided, $4(1.6 \%)$ disagree and $5(2.0 \%)$ strongly disagree with the statement that Internet endnote has negative impact on students' performance $($ mean $=\mathrm{i} 4.37 \mathrm{SD}=.806)$. Further, 33.7\% (86) strongly agree of the respondents, 46(18.7\%) agree, 24(9.8\%) undecided, 50(20.3\%) disagree and 43(17.5\%) strongly disagree with the statement that internet search can enhance students' performance in Biology (Mean=4.27, SD=0.909). Also, 80(32.5\%) strongly agree of the respondents, 69(28\%) agree, 21(8.5\%) undecided, 52(21.1\%) disagree and 24(9.8\%) strongly disagree with the statement that teaching machines integration in ICT can improve students' performance in
Biology (mean=4.30, SD=0.784). However, (32.5\%) strongly agree of the respondents, $69(28 \%)$ agree, 21(8.5\%) undecided, $52(21.1 \%)$ disagree and $24(9.8 \%)$ strongly disagree with the statement that E-learning has negative impact on students' performance (mean=2.30, $\mathrm{SD}=1.534)$. Also, 119(48.4\%) strongly agree of the respondents, 95(38.6\%) agree, 17(6.9\%) undecided, $10(4.1 \%)$ disagree and $5(2.0 \%)$ strongly disagree with the statement that Internet search online take a lot of time which would affect students' performance in Biology (Mean=2.52, SD=1.384).

Another 91(36.9\%) strongly agree of the respondents, $87(35.4 \%)$ agree, $32(13 \%)$ undecided, $28(11.4 \%)$ disagree and $8(3.3 \%)$ strongly disagree with the statement that YOU-TUBE can be a waste of time and may not enhance students' 
performance in Biology $(\mathrm{Mean}=3.58, \mathrm{SD}=1.373)$. Further, $85(34.6 \%)$ strongly agree of the respondents, $65(26.4 \%)$ agree, 26(10.6\%) undecided, 47(19.1\%) disagree and $23(9.3 \%)$ strongly disagree with the statement that teaching machines in ICT may not improve students' performance in Biology $($ Mean=2.30, SD=0.784). Finally, 72(29.3\%) strongly agree of the respondents, $87(35.4 \%)$ agree, $21(8.5 \%)$ undecided, $51(20.7 \%)$ disagree and $15(6.1 \%)$ strongly disagree with the statement that the respondents seem to agree with the statement that YOU-TUBE is good ICT practice that can enhance students' performance in Biology (Mean=3.91, $\mathrm{SD}=1.116$ ).

The study results showed that internet-based tools have a positive influence on students' performance in Biology. This implies that; Internet search and Teaching machines integration in ICT enhance student's performance. The study findings are in agreement with Rajaonah (2017) noted that there are so many internet-based information and communication platforms providing access to search engines for example Google scholar, database software's and other learning applications. These instruments utilize the intensity of web-basedlife to enable students to learn and educator's interface.

The principals and teachers interviewed by the researcher noted that the tool and it is required by the knowledge-based society present the contemporary for information management, information search, communication, research and learning. The use of the internet technology makes it easier for students to obtain more information regarding to Biology quickly and effectively thus improving their performance in the subject. The study findings from interviews revealed internet-based tools have a positive influence on students' performance in Biology. They noted that when students use internet-based tools for learning in terms of internet search for solution to a Biology assignment or discussion they can enhance their Biology performance.

One teacher interview noted that; "students make use of technology tools for learning Biology subject which has influence their performance in Biology"

Further, one principal revealed that; "Few students make use of technology tools in learning Biology in their school despite these technology tools influencing their performance in Biology subject. Iam urging the government and other stakeholders in education sector to provide support in the use of technology in teaching and learning process of Biology subject in order to enhance the subject's performance".

\section{SUMMARY, CONCLUSIONS AND RECOMMENDATIONS}

\section{Summary of the study}

This section presents the summaryof the study findings based on ithe iresearch objective

\section{Influence of internet-based tools on students' performance in Biology in public secondary schools in Likuyani, Kakamega County}

The sought to establish the influence of internet-based tools on students' performance in Biology in public schools in Likuyani, Kakamega County. The study found out that the respondents agreedthat; Internet endnote in ICT can enhance students' performance in Biology, Internetsearch can enhance students'performance in Biology, YOU-TUBE is good ICT practice that can enhance students' performance in Biology and that teaching machines integration in ICT can improve students' performance in Biology.

The study findings showed that internet-based tools were statistically significant with a positive influence on students' performance in Biology. The study results showed that internet-based tools have a positive influence on students' performance in Biology. This implies that Internet endnote in ICT, Internet search and Teaching machines integration in ICT enhances student's performance.

\section{Conclusions of the study research findings}

The study findings concluded that Internet problem solving in ICT, Internet search and Teaching machines integration inICT enhances student's performance.

\section{Recommendations for policy and for practice}

Fromthe findingsofthestudy, it is recommended that;

i. Teachers to be given sufficient training on how to use ICT in teaching and learning processes to acquire the requisite knowledge and skills in integrating technology in classrooms.

\section{REFERENCES}

[1]. Bumia, W. (2018). Emerging technologies for 21st century education- strategies for the use of video mediated instruction. International Journal for Innovative Technology Integration in Education, 1(2), 47-56.

[2]. Castro-Faix, M., Todd, A., Romine, W., \& Duncan, R. (2018). Do Alternative Instructional Approaches Result in Different Learning Progressions?. International Society of the Learning Sciences, Inc.[ISLS].

[3]. Delaney, K., O’Keeffe, M., \& Fragou, O. (2017). A Design Framework for Interdisciplinary Communities of Practice towards STEM Learning in 2 nd Level Education. In International Conference on Interactive Collaborative Learning (pp. 739-750). Springer, Cham.

[4]. Mandinach, E., \& Gummer, E. (2016). What does it mean for teachers to be data literate: Laying out the skills, knowledge, and dispositions? Teaching and Teacher Education, 60, 366-376.

[5]. Rajaonah, B. (2017). A view of trust and information system security under the perspective of critical infrastructure protection. Revue des Sciences et Technologies de l'InformationSérie ISI: Ingénierie des Systèmesd'Information, 22(1), 109.

[6]. Schneider, M., \& Preckel, F. (2017). Variables associated with achievement in higher education: A systematic review of metaanalyses. Psychological Bulletin, 143(6), 565.

[7]. Silberschatz, A., Gagne, G., \& Galvin, P. (2018). Operating system concepts. Wiley. Bazhal, I. (2017). The Political Economy of Innovation Development: Breaking the Vicious Cycle of Economic Theory. Springer. 
[8]. Sorokin, P. (2017). Social and cultural dynamics: A study of change in major systems of art, truth, ethics, law and social relationships. Routledge.

[9]. Strogatz, S. (2018). Nonlinear dynamics and chaos: with applications to physics, Biology, chemistry, and engineering. CRC Press.

[10]. Sumich, J., \& Pinkard-Meier, D. (2016). Introduction to the Biology of marine life. Jones \& Bartlett Learning.
[11]. Van Wormer, K., \&Besthorn, F. (2017). Human behavior and the social environment, macro level: Groups, communities, and organizations. Oxford University Press.

[12]. Witten, I., Frank, E., Hall, M., \& Pal, C. (2016). Data Mining: Practical machine learning tools and techniques. Morgan Kaufmann. 